\title{
Symptomatic benign pleural effusions among asbestos insulation workers: residual radiographic abnormalities
}

\author{
RUTH LILIS, YEHUDA LERMAN, I J SELIKOFF
}

From the Division of Environmental and Occupational Medicine, Mount Sinai School of Medicine of the City University of New York, New York, New York 10029, USA

ABSTRACT During a cross sectional medical survey of 2815 insulation workers with 30 years or more from onset of asbestos exposure conducted from 1981 to 1983, a positive history of benign pleural effusion was found in $20(0 \cdot 71 \%)$. Two or three such episodes had occurred in four of these 20 subjects. The chest $x$ ray abnormalities in these cases were characterised by pleural fibrosis in 19 and diffuse pleural fibrosis with blunting of the corresponding costophrenic angle in 16. In the total group of 2815 insulation workers diffuse pleural fibrosis was found in $142(5.0 \%)$. Thus diffuse pleural fibrosis with blunting of the corresponding costophrenic angle is a frequent residual abnormality after benign pleural effusion. Its impact on pulmonary function can be pronounced.

The association of asbestos exposure with non-malignant and malignant pleural changes, such as pleural fibrosis, pleural calcification, and malignant pleural mesothelioma, has gradually gained general acceptance over the past few decades. Benign pleural effusion, a less frequent occurrence in asbestos exposed subjects, has attracted attention as a specific asbestos related entity only more recently. ${ }^{1-3}$ Several case reports and clinical studies have contributed to the description of its natural history among asbestos exposed workers. ${ }^{4-11}$

In some cases the clinical onset may be acute, with fever, chest pain, leucocytosis, and raised ESR; in other cases, probably the majority, the onset is insidious with few symptoms; the condition can even be completely asymptomatic.

Most publications on asbestos induced benign pleural effusions have been clinical case reports, although one reviewed the incidence of benign pleural effusion in an occupationally heterogenous group of workers exposed to asbestos, including shipyard employees and fireproofing product manufacturing and paper mill workers, who were re-examined at yearly intervals for at least three and up to 15 years."

We have recently completed a comprehensive clinical survey of 2815 asbestos insulation workers with more than 30 years from onset of exposure. Previous occurrence of pleural effusion was systematically

Accepted 22 June 1987 recorded in the medical questioning of the workers. We report here the frequency of a positive history of pleural effusion in this group, the duration from onset of asbestos exposure to the occurrence of the pleural effusion, and the residual radiological findings at the time of the survey.

\section{Methods}

A cohort of asbestos insulation workers in the United States and Canada was established on 1 January $1967 .^{12}$ It included all 17800 members on the rolls of the insulation workers union (the International Association of Heat and Frost Insulators and Asbestos Workers (IAHFIAW), AFL-CIO, CIC) in the United States and Canada on that day. The mortality experience of this cohort 1967-77 has been reported; there were 66 instances of pleural mesothelioma among the 2271 deaths. ${ }^{13}$

A total of 5377 members of the cohort who were alive in 1981 and had reached 30 years from onset of work exposure were invited to appear for a comprehensive medical examination: 2815 were examined in 1981-3.* The examinations included occupational, medical, and smoking history, review of symptoms,

*Examinations were undertaken in Chicago, Columbus, Baltimore Boston, Atlanta, Tampa, Seattle, Anchorage, San Francisco, Los Angeles, Denver, Omaha, St Louis, Alburquerque, Dallas, Houston, New Orleans, New York, New Jersey, and Syracuse from November 1981 to October 1983. 


\begin{tabular}{|c|c|c|c|}
\hline Patient No & Age at time of pleural effusion & $\begin{array}{l}\text { Duration from onset of asbestos } \\
\text { exposure to pleural effusion (years) }\end{array}$ & $\begin{array}{l}\text { Interval between pleural } \\
\text { effusion and examination (years) }\end{array}$ \\
\hline $\begin{array}{c}1 \\
2 \\
3 \\
4 \\
5 \\
6 \\
7 \\
8 \\
9 \\
10 \\
11 \ddagger \\
12 \\
13 \\
14 \\
15 \\
16 \\
17 \\
18 \\
19 \\
20\end{array}$ & $\begin{array}{l}55 \\
22 \\
29 \\
59 \\
68 \\
53 \\
59 \\
33 \\
30 \\
43 \\
81 \\
45 \\
27 \\
58 \\
34 \\
55 \\
42 \\
53 \\
38 \\
52\end{array}$ & $\begin{array}{r}33 \\
1 \\
9 \\
34 \\
53 \\
32 \\
41 \\
21 \\
12 \\
22 \\
62 \\
7 \\
9 \\
37 \\
14 \\
39 \\
22 \\
31 \\
21 \\
22\end{array}$ & $\begin{array}{r}3 \\
32 \\
24 \\
8 \\
1 \\
3 \\
3 \\
9 \\
31 \\
13 \\
2 \\
36 \\
21 \\
4 \\
24 \\
2 \\
10 \\
2 \\
13 \\
19\end{array}$ \\
\hline
\end{tabular}

*ILO International Classification of Radiographs of Pneumoconioses, 1980.

$\dagger$ Diffuse pleural thickening.

$\ddagger$ Patient died one year after examination; ascertained cause of death according to necropsy was arteriosclerotic heart disease.

respiratory questionnaires, physical examination, chest $x$ ray films, pulmonary function tests, and laboratory tests.

The pleural effusion was accepted as "definite" when the examinee knew that there had been "fluid in the chest" or when thoracentesis ("pleural tap") had been performed. Reports of "pleurisy" were followed up by questions on possible accumulation of fluid in the chest or on attempts at thoracentesis. These generally resulted in negative answers and were not included as definite pleural effusions.

We present here the responses regarding the frequency of benign pleural effusion, as reported in the medical histories, in these 2815 asbestos insulation workers. The duration from onset of asbestos exposure to the time when the effusion occurred and the residual chest $x$ ray abnormalities present in these cases were of special interest. Chest radiographs were interpreted according to the ILO International Classification of Radiographs of Pneumoconioses (1980) ${ }^{14}$ by an experienced " $B$ " reader.

\section{Results}

Twenty $(0 \cdot 71 \%)$ of the 2815 examinees had a history of definite pleural effusion.

Pleural effusion, whether a single episode or recurrent, is a common disorder. The causes are numerous; among those usually listed one may find chest trauma, tuberculosis, pneumonia, uncommon infections, rheumatoid disease, lupus, drugs such as nitrofurantoin, sarcoidosis, postmyocardial infarction syndrome, and others. ${ }^{1516}$ All patients in our series lacked evidence of any of these diseases.

The table shows the time of the pleural effusion, time lapse (years) between first exposure to asbestos and pleural effusion, interval between pleural effusion and examination, and radiological findings at the time of the 1981-3 examinations for the 20 cases with a definite history of pleural effusion.

Four of the 20 cases had had two or more episodes of pleural effusion: the interval between the first and the second episode varied between one year in two subjects and nine years in one case. One of these four cases was found to have had a third episode.

The interval between onset of exposure to asbestos and the occurrence of pleural effusion varied between one and 62 years. In only four cases was the interval shorter than 10 years.

Of particular interest were the radiological abnormalities in the cases with history of definite pleural effusions in the past. In 19 pleural fibrosis was present. In most (16) the pleural fibrosis was diffuse, with blunting of the corresponding costophrenic angle (figs 1-3). In another three cases circumscribed pleural thickening (as defined by the ILO classification, 1980) was found..$^{14}$ Parenchymal abnormalities (small irregular opacities) $1 / 0$ or more were associated with pleural fibrosis in 12 cases $(60 \%)$. Profusion of small irregular opacities was graded $0 / 0$ or $0 / 1$ in six cases and $1 / 0$ or above in 14 cases according to the ILO classification $1980 .{ }^{14}$ The chest $x$ ray film was normal in only one of the 20 cases. 


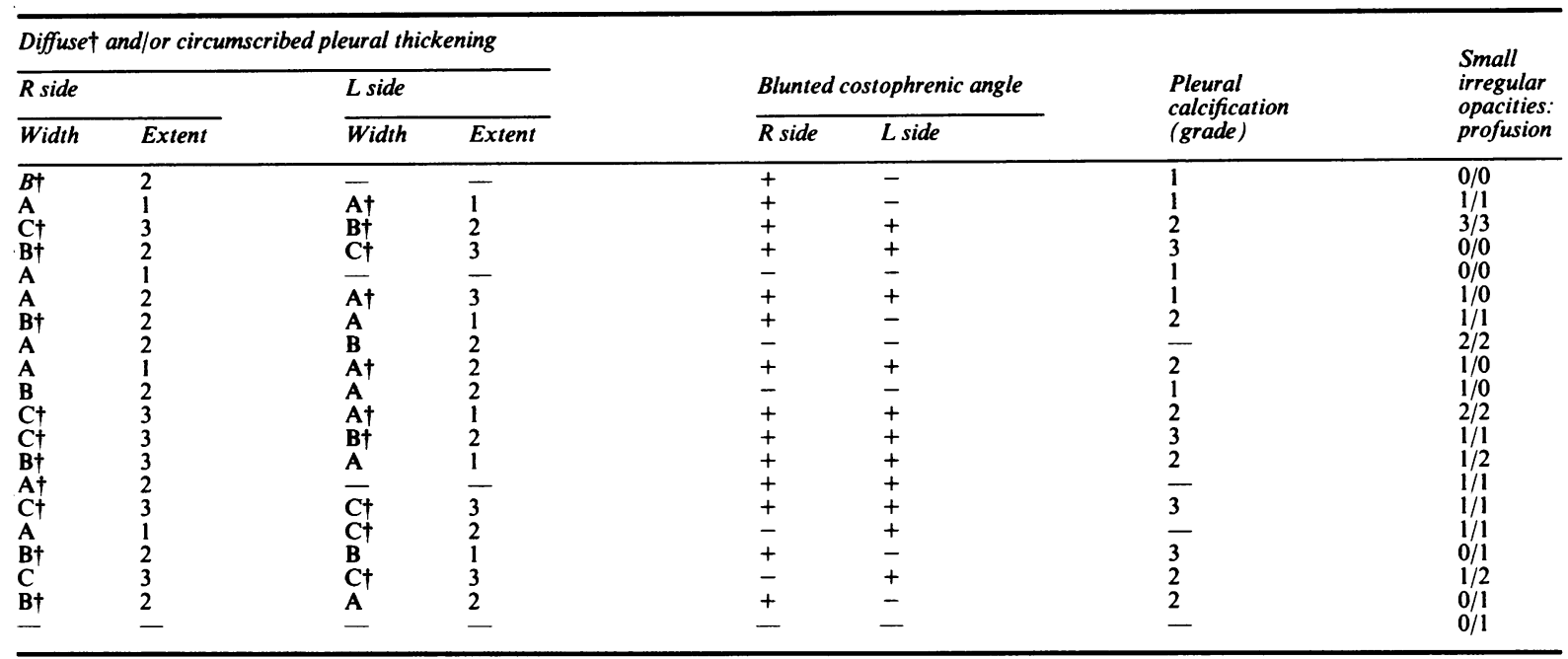

In seven cases the diffuse pleural fibrosis was of considerable thickness, exceeding $1 \mathrm{~cm}$ (width $\mathrm{C}$ ). Pleural fibrosis was extensive, affecting more than half of the lateral projection of the chest wall (extent 3 ) in eight cases; in six of these the thickness of the fibrosed pleura was graded $C(>1 \mathrm{~cm})$.

In 16 cases there was evidence of pleural calcification; in most, calcification was grade 2 or 3 according to the ILO Classification (1980). ${ }^{14}$

The prevalence of diffuse pleural fibrosis with involvement of the ipsilateral costophrenic angle in the total examined population of 2815 asbestos insulation workers was also assessed. The frequency $(80 \%)$ of diffuse pleural fibrosis in the 20 cases with definite pleural effusion by history was much higher than that found in the total group of 2815 examined asbestos insulation workers. The total number of cases with diffuse pleural fibrosis was $142(5 \cdot 0 \%)$. In 94 cases (3.3\%) diffuse pleural fibrosis was unilateral and in 48 $(1.7 \%)$ such changes were found bilaterally. Thus when a positive history of pleural effusion was obtained, the probability of diffuse pleural fibrosis on the chest $x$ ray film was about 16 times higher than in the other examined asbestos insulation workers.

\section{Discussion}

Benign asbestotic pleural effusion as a specific asbestos related entity was first reported in the early 1960s after other asbestos induced pleural changes, such as pleural fibrosis, calcification, and malignant mesothelioma, had been described. ${ }^{\text {Is }}$

Eisenstadt described this entity as recurrent episodes of idiopathic pleurisy presenting with chest pain and radiological findings compatible with the diagnosis of pleural effusion; serous to bloody pleural fluid often accumulated and eventually extensive pleural adhesions obliterated the pleural cavity. ${ }^{1-3}$ Chahinian, in 1973, indicated that benign asbestotic pleural effusion was rarely reported; he collected 30 cases from published reports and reported six personal cases. ${ }^{8}$ Gaensler and Kaplan first suggested that asbestos pleural effusion was not uncommon; they found 12 cases of pleural effusion among 57 patients with asbestosis examined in their department. ${ }^{5}$

In 1982 Epler et al reported $34(3 \cdot 1 \%)$ benign effusions among 1135 exposed workers in various trades; among 717 control subjects no otherwise unexplained pleural effusions occurred."

The 2815 subjects in our study are a homogeneous group of asbestos insulation workers, members of a cohort established in 1967, each with 30 or more years since onset of asbestos exposure at the time of examination 1981-3. A positive history of pleural effusion was reported by $20(0 \cdot 71 \%)$. This was less than the $3.1 \%$ reported in the study by Epler et al." The difference may be explained by the different characteristics of the studies. The population studied by Epler $e t$ al were active workers examined repeatedly at yearly intervals. The criteria for benign asbestos related pleural effusion were (1) direct or indirect exposure to asbestos, (2) an effusion confirmed by thoracentesis or a transient pleural change in serial chest films, (3) lack of evidence for any other disease related to pleural effusion, and (4) no malignant tumour detected within three years after the effusion." These criteria allowed asymptomatic cases to be included in Epler's study. 


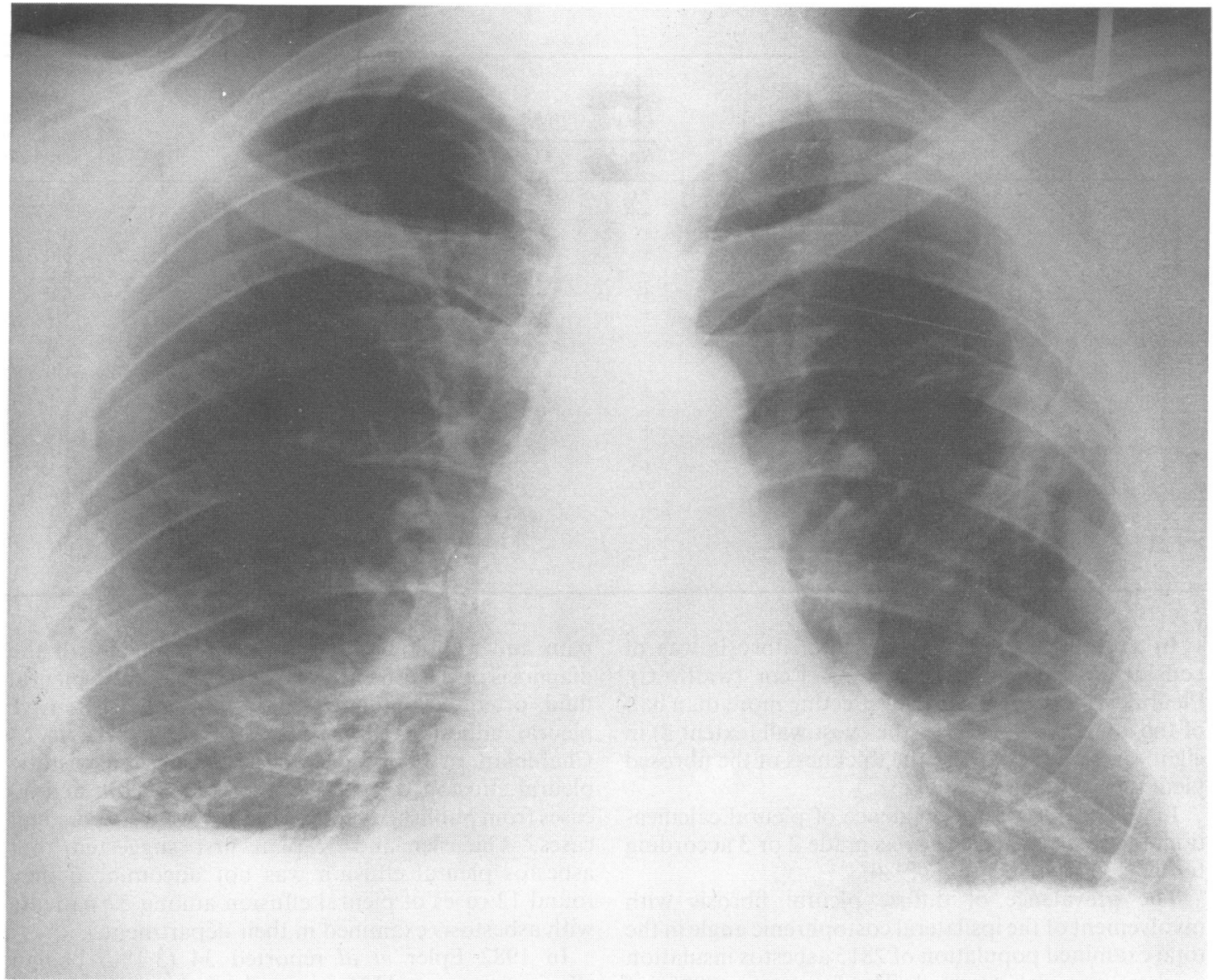

Fig 1 Extensive bilateral diffuse pleural fibrosis in a 58 year old insulator. Pleural effusion had occurred 14 years after onset of exposure to asbestos.

In the present series only symptomatic cases were included; the examinee had to have been aware of this condition in the past, the condition had to have been brought to the attention of a physician by the patient, and had to have been diagnosed as pleural effusion.

Since it is thought that benign pleural effusion may go entirely unnoticed by more than half the patients, ${ }^{\prime \prime}$ the true frequency in our series might have been higher than the 20 cases who reported a definite history of pleural effusion. The problem of recall for periods as long as $\mathbf{3 0}$ or more years most probably also resulted in an underestimate of the true frequency of benign pleural effusion in our study population.

In one case the pleural effusion was relatively recent (one year before the examination); in seven other cases the interval between pleural effusion and examination was between two and four years. A follow up of the eight cases for three to five years after examination has not shown development of malignant pleural mesothelioma in any of them.

The high frequency of diffuse pleural thickening with blunted costophrenic angle among the 20 cases with positive history of pleural effusion is consistent with findings reported by other investigators." The prevalence $(5.0 \%)$ of radiologically evident diffuse pleural fibrosis in the total group of asbestos insulation workers studied raises the possibility that these radiological changes may be, at least in some of the cases, residual after asymptomatic pleural effusion.

Epler $e t$ al suggested that the latency period between first exposure to asbestos and clinical evidence of pleural effusion was shorter than for other asbestos related disorders. "It was the only manifestation seen within ten years from onset of exposure. In our series 


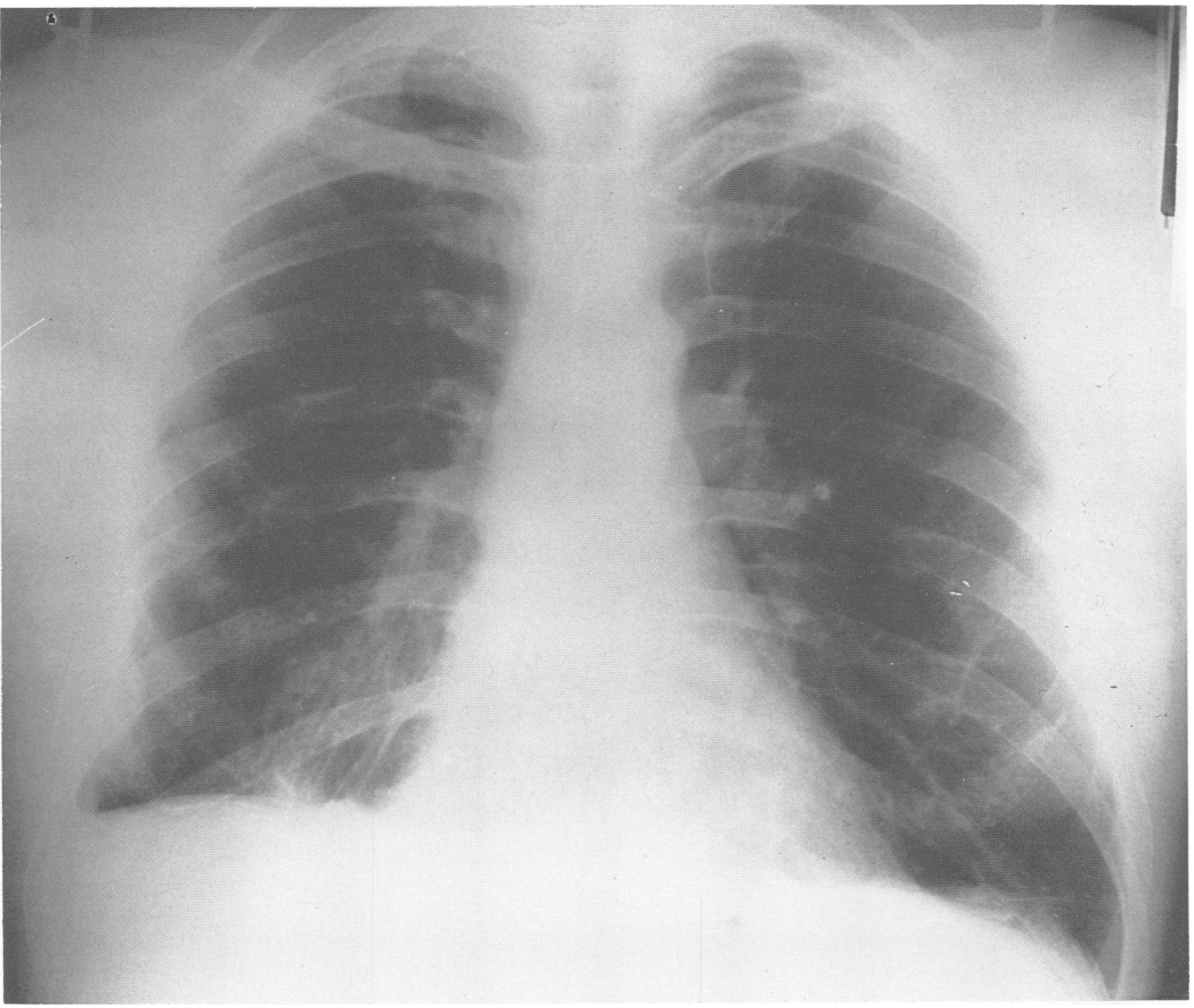

Fig 2 Right diffuse pleural fibrosis in a 52 year old insulator. Right pleural effusion had occurred 22 years after onset of exposure.

we encountered four patients who developed benign pleural effusion within ten years from onset of asbestos exposure; in the other 16 cases the interval between onset of asbestos exposure until the development of the pleural effusion was considerably longer. Other investigators have also reported asbestos related benign pleural effusions decades after onset of exposure. $^{568}$

\section{Conclusion}

Benign asbestotic pleural effusion is part of the spectrum of asbestos related pleural changes. It seems to be a less infrequent phenomenon than previously thought.
Diffuse pleural thickening with concomitant blunted costophrenic angle is the most frequent residual radiological abnormality after benign pleural effusion. The functional impact of such pleural abnormalities can be pronounced. ${ }^{17}$

This and other reported studies emphasise the need to search for an occupational or environmental ${ }^{18}$ exposure to asbestos whenever a patient presents with a pleural effusion of undetermined origin.

We thank Ms Judith Malkin for technical help and Mr Sidney Sibel for typing the manuscript.

This research was supported in part by Center Grant ES 00928 of the National Institute of Environmental 


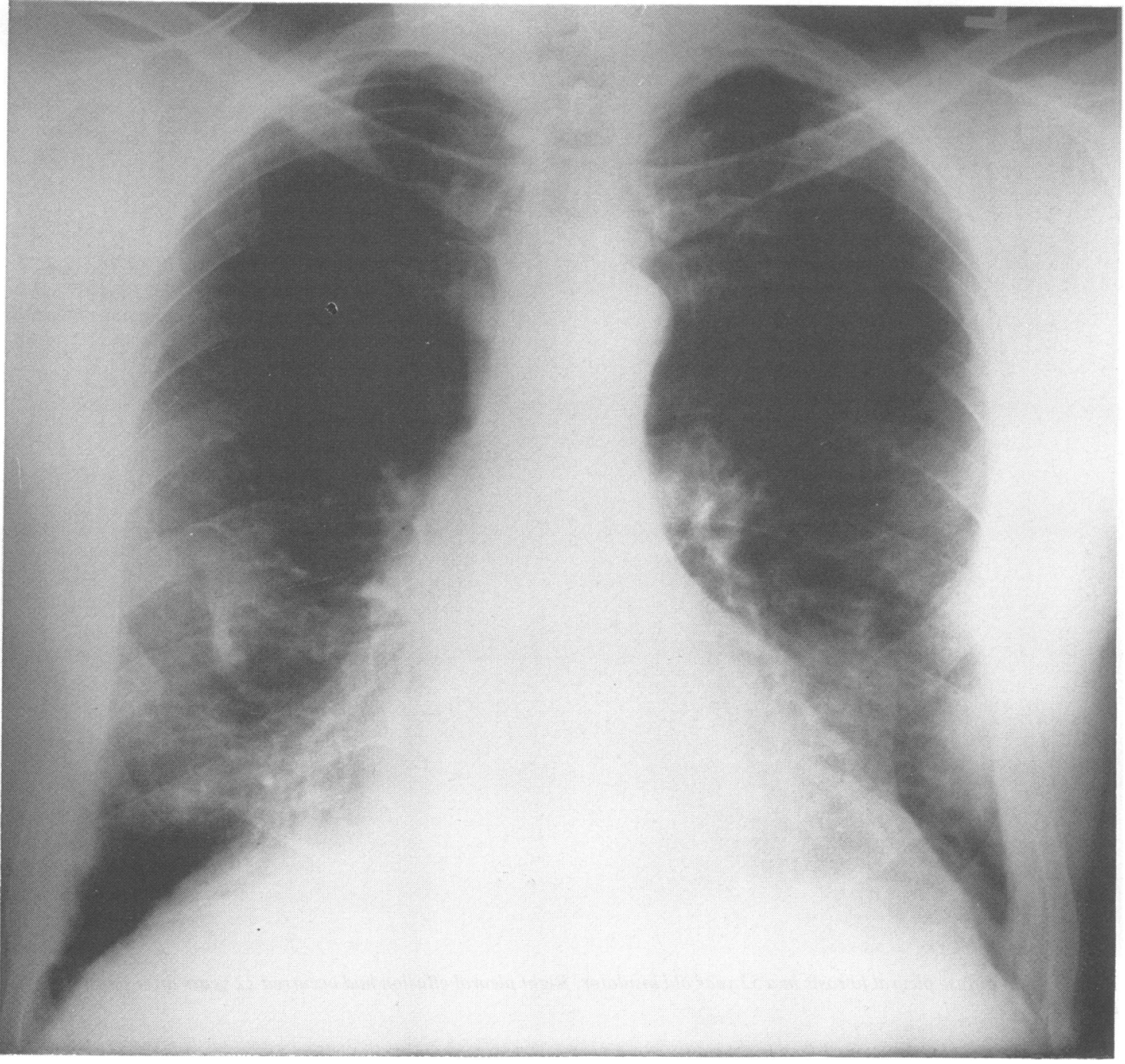

Fig 3 Extensive bilateral pleural fibrosis; right costophrenic angle is not blunted. Left pleural effusion had occurred 31 years after onset of exposure in this 55 year old insulator.

Health Sciences, US Department of Health and Human Services.

Requests for reprints to: Dr Ruth Lilis, Division of Environmental and Occupational Medicine, Department of Community Medicine, Mount Sinai School of Medicine, 1 Gustave L Levy Place, New York, NY 10029.

\section{References}

1 Eisenstadt HB. Pleural asbestosis. American Practitioner 1962;13:573-8.
2 Eisenstadt HB. Asbestos pleurisy. Dis Chest 1964;46:78-81.

3 Eisenstadt HB. Benign asbestos pleurisy. JAMA 1965;192:419-21.

4 Collins TFB. Pleural reaction associated with asbestos exposure. Br J Radiol 1968;41:655-61.

5 Gaensler EA, Kaplan AI. Asbestos pleural effusion. Ann Intern Med 1971;74:178-91.

6 Smyth NPD, Goodman NG, Basu AP, Keshishian JM. Pulmonary asbestosis. Chest 1971;60:270-3.

7 Sluis-Cremer GK, Webster I. Acute pleurisy in asbestos-exposed persons. Environ Res 1972;5:380-92.

8 Chahinian P, Hirsch A, Bignon J, et al. Les pleurésies asbestosiques non tumorales. Revue Française des Maladies Respiratoires 1973;1:5-39.

9 Boutin C, Viallat J, Farisse P, Choux R. Pleuresies asbestosiques bénignes. Poumon et le coeur 1975;31:111-8. 
10 Leménager $J$, Rousselot $P$, LeBouffant $L$, Bénard Y. Les pleurésies bénignes de lámiante. Revue Française des Maladies Respiratoires 1975:3:325-42.

11 Epler GR, McLoud TC, Gaensler EA. Prevalence and incidence of benign asbestos pleural effusion in a working population. JAMA 1982;247:617-22.

12 Selikoff IJ. Hammond EC, Seidman H. Cancer risk of insulation workers in the United States. In: Bogovski P. Gilson JC, Timbrell V, Wagner JC. Biological effects of asbestos. Lyon: International Agency for Research on Cancer, 1973:209-16. (IARC sci publ No 8.)

13 Selikoff IJ, Hammond EC, Seidman H. Mortality experience of insulation workers in the US and Canada 1943-1976. Ann NY Acad Sci 1979:330:91-116.
14 International Labour Office. The ILO international classification of radiographs of pneumoconioses, 1980. Geneva: ILO, 1980. (Occupational safety and health series No 22 (rev).)

15 Parks WR. Disorders presumed to be related to asbestos exposure. Benign pleural effusion and lone diffuse pleural thickening. In: Occupational lung disorders. 2nd ed. London, Boston: Butterworth, 1983:293-4.

16 Storey DD, Pines DE, Coles DT. Pleural effusion: a diagnostic dilemma. JAMA 1976;236:2183-6.

17 Miller A, Teirstein AS, Selikoff IJ. Ventilatory failure due to asbestos pleurisy. Am J Med 1983;75:911-9.

18 Epler GR, FitzGerald MX, Gaensler EA, Carrington CB. Asbestos-related disease from household exposure. Respiration 1980;35:229-40.

\section{Correspondence and editorials}

The British Journal of Industrial Medicine welcomes correspondence relating to any of the material appearing in the journal. Results from preliminary or small scale studies may also be published in the correspondence column if this seems appropriate. Letters should be not more than 500 words in length and contain a minimum of references. Tables and figures should be kept to an absolute minimum. Letters are accepted on the understanding that they may be subject to editorial revision and shortening.

The journal now also publishes editorials which are normally specially commissioned. The Editor welcomes suggestions regarding suitable topics; those wishing to submit an editorial, however, should do so only after discussion with the Editor. 